\title{
Intrarater reliabilities of shoulder joint horizontal adductor muscle strength measurements using a handheld dynamometer for geriatric and stroke patients
}

\author{
Masahiro Hirano, PT, MS ${ }^{1)^{*}}$, Munenori Katoh, PT, PhD ${ }^{1)}$, Saori Kawaguchi, $\mathrm{PT}^{2)}$, \\ Tomomi Uemura, $\mathrm{PT}^{2)}$ \\ 1) Department of Physical Therapy, Faculty of Health Sciences, Ryotokuji University: 5-8-1 Akemi, \\ Urayasu City, Chiba 279-8567, Japan \\ 2) Department of Rehabilitation, Higashi Funabashi Hospital, Japan
}

\begin{abstract}
Purpose] This study aimed to verify the appropriate number of measurements and the intrarater reliabilities of shoulder joint horizontal adductor muscle strength measurements using a handheld dynamometer (HHD) for geriatric and stroke patients. [Subjects and Methods] The subjects were 40 inpatients, who were divided into two groups: 20 stroke patients in the stroke group (SG), and 20 geriatric patients in the no-stroke group (N-SG). Measurements were performed three times using an HHD with a belt. The reliability was verified using BlandAltman analysis and the intraclass correlation coefficient (ICC). [Results] ICC $(1,1)$ was $>0.9$. A systematic bias was not observed between the first and second measurement values except for the right side in N-SG. A systematic bias between the maximum value obtained during the first and second measurements and third measurement value was observed on the left side in N-SG, and on the non-paralyzed side in SG: the third measurement values were small in both cases. [Conclusion] Intrarater reliabilities were high for shoulder horizontal adductor strength measurements using an HHD with a belt for geriatric and stroke patients. Taking the systematic bias into consideration, these findings suggest that the required number of measurements is two.

Key words: Intrarater reliability, Handheld dynamometer, Shoulder joint horizontal adductor strength
\end{abstract}

(This article was submitted Aug. 28, 2015, and was accepted Oct. 5, 2015)

\section{INTRODUCTION}

Aging is associated with an increased risk of developing respiratory impairment ${ }^{1}$. After a stroke, respiratory function is impaired $^{2}$. Lung function tests are not necessarily conducted in rehabilitation, sometimes because there is no examination equipment. Ortega et al. ${ }^{3)}$ reported that upper limb training, including a "Butterfly" (mainly for the pectoralis major muscle) is to improves the ratio of dyspnea in chronic obstructive pulmonary disease with respiratory dysfunction. Therefore, it appears thought that the shoulder joint horizontal adductor muscles on the rib cage are involved in respiratory function. Shoulder joint horizontal adductor muscle strength measurements could be used as an alternative evaluation of cases for whom lung function tests are difficult. Accordingly, this study examined a measurement method of shoulder joint horizontal adductor muscle strength using geriatric and stroke patients.

Muscle strength measurements using a handheld dynamometer (HHD) consist of two types: a "make test" and a "break test." One limitation of using an HHD is that the make test cannot measure the maximum muscle strength of a subject if the examiner cannot resist the subject's movement. Another limitation of an HHD is that the break test cannot measure the

\footnotetext{
*Corresponding author. Masahiro Hirano (E-mail: m-hirano@ryotokuji-u.ac.jp)

(C)2016 The Society of Physical Therapy Science. Published by IPEC Inc.

This is an open-access article distributed under the terms of the Creative Commons Attribution Non-Commercial No Derivatives (by-nc-nd) License $<$ http://creativecommons.org/licenses/by-nc-nd/3.0/>.
} 
Table 1. General and medical characteristics of subjects

\begin{tabular}{|c|c|c|c|c|}
\hline & & $\mathrm{SG}(\mathrm{n}=20)$ & \multicolumn{2}{|l|}{ N-SG $(n=20)$} \\
\hline Gender (male, female) & & $(14,6)$ & \multicolumn{2}{|l|}{$(11,9)$} \\
\hline Age (years) & & $75.0 \pm 6.6(66-84)$ & \multicolumn{2}{|l|}{$80.2 \pm 6.2(67-91)$} \\
\hline Height (cm) & & $159.2 \pm 10.3(136-178)$ & \multicolumn{2}{|l|}{$152.2 \pm 8.5(137-170)$} \\
\hline Body weight (kg) & & $58.3 \pm 12.6(42-81)$ & \multicolumn{2}{|l|}{$47.7 \pm 9.7(31-64)$} \\
\hline Onset dates (days) & & $13.8 \pm 10.4(3-41)$ & \multicolumn{2}{|l|}{$24.8 \pm 24.6(5-103)$} \\
\hline Disease state & \multicolumn{4}{|c|}{ Disease state } \\
\hline Intracerebral hemorrhage & & 4 & pneumonia & 9 \\
\hline Cerebral infarction & & 12 & Pelvic fracture & 1 \\
\hline Subdural hemorrhage & & 3 & Spinal compression fracture & 4 \\
\hline Hemorrhagic infarction & & 1 & Bruise of head or general body & 2 \\
\hline Paralyzed side (right/left) & & $12 / 8$ & Dehydration & 1 \\
\hline \multirow[t]{4}{*}{ SIAS Knee-Mouth Test score } & 5 & 7 & Cancer & 1 \\
\hline & 4 & 12 & Acute renal failure & 1 \\
\hline & 3 & 1 & Diabetes mellitus & 1 \\
\hline & $2-0$ & 0 & & \\
\hline
\end{tabular}

Mean \pm SD (range), SG: stroke group, N-SG: no-stroke group

maximum muscle strength of a subject if the subject cannot maintain the position. Previous studies have reported that $30 \mathrm{~kg}$ $(300 \mathrm{~N})$ is the fixed limit for an HHD in the make test $\left.{ }^{4}, 5\right)$. Katoh et al. devised a method of using a belt as a countermeasure to the fixed HHD limit when measuring lower limbs with high muscle strength values and reported on the reliability of this method for a variety of subjects ${ }^{6-9}$. . Our research group has also reported on the usefulness of the belt with a fixed HHD limit for shoulder joint horizontal adductor muscle strength measurements of young healthy Japanese adults ${ }^{10)}$ and its reliability ${ }^{11)}$. However, the reliability of this method in the measurement of geriatric and non-healthy individuals has not yet been reported. Few measurements and high reliability are necessary to reduce the patient burden in the evaluation of geriatric patients and stroke patients presenting with motor paralysis. The purpose of this study was to examine the appropriate number of measurements and the intrarater reliabilities of shoulder joint horizontal adductor muscle strength measurements using an HHD with a belt for geriatric and stroke patients.

\section{SUBJECTS AND METHODS}

The subjects were 40 inpatients over the age of 65 years (onset days, 3-103). They were divided into two groups: 20 stroke patients in the stroke group (SG), and 20 geriatric patients in the no-stroke group (N-SG). Subjects were included in the SG only if the movement of shoulder joint horizontal adduction was possible with a Japanese Coma Scale (JCS) score of 1. Subjects were included in N-SG if neurological and orthopedic abnormalities were absent from the upper limbs. Table 1 shows the subject characteristics.

All shoulder joint horizontal adductor muscle strength measurements were performed with the subjects lying on an examination table in the supine position. The shoulder joint of each subject was abducted to $90^{\circ}$, with $0^{\circ}$ internal and external rotation, and the elbow joint was flexed to $90^{\circ}$. The subject was positioned such that the shoulder joint was aligned with the bedpost. The elbow on the measurement side was positioned on the edge of the examination table.

The equipment used for shoulder joint horizontal adductor muscle strength measurements was a $\mu$ TAS F-1 HHD (Anima Corp., Tokyo, Japan). The sensor was placed on a thin rubber pad, which was fixed to the distal part of the upper arm with a surface fastener. The belt was fitted with sensors and inserted between the bedpost and the floor to fix the HHD. The examiner was a 32-year-old male physical therapist, $168 \mathrm{~cm}$ in height and $60 \mathrm{~kg}$ in weight, with 10 -year-experience. The examiner controlled his hand in such a way so as not to move the HHD sensor and placed his other hand on the anterior aspect of the opposite shoulder joint to suppress compensatory movements. Figure 1 shows the measuring method. Subjects were asked to perform isometric contractions in a manner similar to the make test. Maximum contractions were attained within $3 \mathrm{~s}$ and were maintained for $5 \mathrm{~s}$. The maximum values of shoulder joint horizontal adductor muscle strength were recorded. All measurements were performed after practice and prior orientation. In addition, all measurements were performed on the same day, three consecutive times on each side, at 30-s intervals.

Reliability was verified using three measurements, the maximum value obtained during the first and second measurements and the maximum value obtained during the first and second measurements and the third measurement. Differences in the five values were compared between the two groups. The difference in mean values was assessed using one-way analysis of variance with the Scheffe multiple comparison procedure. Reliability was verified using intrarater reliability as assessed by 


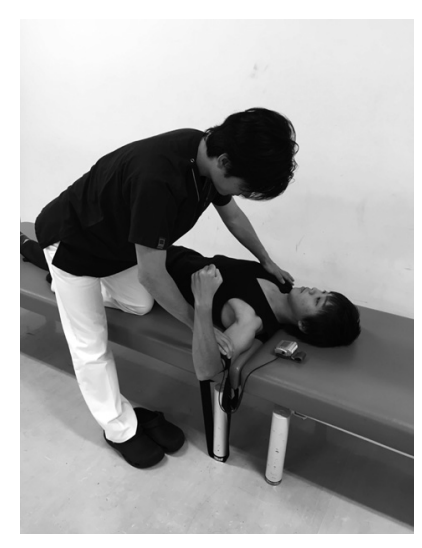

Fig. 1. Measurering method (image)

Table 2. Shoulder joint horizontal adductor muscle strength (ratio muscle strength/body weight)

\begin{tabular}{|c|c|c|c|c|}
\hline & \multicolumn{2}{|c|}{$\mathrm{SG}(\mathrm{n}=20)$} & \multicolumn{2}{|c|}{ N-SG $(n=20)$} \\
\hline & $\begin{array}{c}\text { Non-paralyzed } \\
\text { side }\end{array}$ & $\begin{array}{l}\text { Paralyzed } \\
\text { side }\end{array}$ & $\begin{array}{l}\text { Right } \\
\text { side }\end{array}$ & $\begin{array}{l}\text { Left } \\
\text { side }\end{array}$ \\
\hline $1 \mathrm{st}(\mathrm{kgf} / \mathrm{kg})$ & $0.27 \pm 0.12^{\dagger}$ & $0.25 \pm 0.12^{\dagger^{*}}$ & $0.19 \pm 0.08^{\dagger^{*}}$ & $0.18 \pm 0.09$ \\
\hline 2nd (kgf/kg) & $0.26 \pm 0.11^{\dagger *}$ & $0.25 \pm 0.13^{\dagger}$ & $0.20 \pm 0.08^{\dagger}$ & $0.19 \pm 0.08^{\dagger}$ \\
\hline $3 \mathrm{rd}(\mathrm{kgf} / \mathrm{kg})$ & $0.25 \pm 0.10^{\dagger}$ & $0.24 \pm 0.11$ & $0.20 \pm 0.07^{\dagger}$ & $0.18 \pm 0.08^{\dagger}$ \\
\hline The maximum value obtained during the $1 \mathrm{st}$ and $2 \mathrm{nd}(\mathrm{kgf} / \mathrm{kg})$ & $0.28 \pm 0.12$ & $0.26 \pm 0.13$ & $0.21 \pm 0.08$ & $0.19 \pm 0.08$ \\
\hline The maximum value $(\mathrm{kgf} / \mathrm{kg})$ & $0.28 \pm 0.11$ & $0.27 \pm 0.13$ & $0.21 \pm 0.07$ & $0.20 \pm 0.20$ \\
\hline
\end{tabular}

Mean \pm SD (range), SG: stroke group, N-SG: no-stroke group

†: vs. The maximum value, $\mathrm{p}<0.05, *$ : vs. The maximum value obtained during the 1 st and 2 nd, $p>0.05$

No significant difference between the non-paralyzed side vs. paralyzed side, and between the right side vs. left side.

Table 3. ICC of shoulder joint horizontal adductor muscle strength

\begin{tabular}{llcc}
\hline Group & Measurement side & ICC $(1,1)$ & $95 \% \mathrm{CI}$ \\
\hline SG & non-paralyzed & 0.937 & $0.874-0.972$ \\
& paralyzed & 0.920 & $0.843-0.965$ \\
N-SG & right & 0.930 & $0.861-0.969$ \\
& left & 0.943 & $0.886-0.975$ \\
\hline
\end{tabular}

SG: stroke group, N-SG: no-stroke group, ICC (1,1): intra-rater correlation coefficients, $95 \%$

CI: $95 \%$ confidence interval

the intraclass correlation coefficient (ICC) $(1,1)$ and Bland-Altman analysis (BAA). The required number of measurements was evaluated using statistical software (R2.8.1). BAA was performed using the first and second measurements as well as the maximum value obtained during the first and second measurements and the third measurement. A probability (p) value of $<0.05$ was considered to be statistically significant.

The study protocol was approved by the ethics committee of Ryotokuji University (approval number: 2632) and was in accordance with the Declaration of Helsinki. Informed consent was obtained from each subject before participation.

\section{RESULTS}

The mean and standard deviation of shoulder joint horizontal adductor muscle strength measurements are shown in Table 2. The results of ICC $(1,1)$ were $\geq 0.92$ (Table 3). The results of BAA are shown in Table 4 . In SG, there was no systematic bias on either side between the first and second measurement values. The third measurement value was smaller than the maximum value obtained during the first and second measurements. In N-SG, a systematic bias was observed between the first and second measurement values on the right side. However, no systematic bias was observed between the maximum value obtained during the first and second measurements and the third measurement value, and no systematic bias was observed between the first and second measurement values on the left side. On both sides, the third measurement value 
Table 4. Bland-Altman analysis of shoulder joint horizontal adductor muscle strength measurements

\begin{tabular}{|c|c|c|c|c|c|c|c|c|}
\hline \multirow[b]{2}{*}{ Group } & \multirow{2}{*}{$\begin{array}{l}\text { Measurement } \\
\text { side }\end{array}$} & \multirow[b]{2}{*}{ Comparison } & \multicolumn{2}{|l|}{ Fixed bias } & \multicolumn{2}{|c|}{ Proportional bias } & \multirow[b]{2}{*}{ LOA } & \multirow{2}{*}{$\begin{array}{l}\mathrm{MDC}_{95} \\
(\mathrm{kgf} / \mathrm{kg})\end{array}$} \\
\hline & & & $95 \% \mathrm{CI}$ & Bias* & $\begin{array}{l}\text { Slope of the } \\
\text { regression line }\end{array}$ & Bias* & & \\
\hline \multirow{4}{*}{$\begin{array}{l}\text { SG } \\
(n=20)\end{array}$} & non-paralyzed & A & -0.01 to 0.03 & n-ex & 0.033 & n-ex & -0.03 to 0.06 & 0.08 \\
\hline & & B & 0.01 to 0.04 & ex & 0.166 & ex & -0.02 to 0.07 & 0.08 \\
\hline & paralyzed & A & -0.02 to 0.01 & n-ex & -0.016 & n-ex & -0.04 to 0.04 & 0.07 \\
\hline & & B & 0.001 to 0.05 & n-ex & 0.152 & n-ex & -0.03 to 0.09 & 0.10 \\
\hline \multirow{4}{*}{$\begin{array}{l}\text { N-SG } \\
(\mathrm{n}=20)\end{array}$} & right & A & -0.03 to -0.001 & ex & 0.011 & n-ex & -0.04 to 0.02 & 0.05 \\
\hline & & B & -0.002 to 0.02 & n-ex & 0.142 & n-ex & -0.02 to 0.03 & 0.05 \\
\hline & left & A & -0.02 to 0.01 & n-ex & 0.122 & n-ex & -0.04 to 0.03 & 0.06 \\
\hline & & $\mathrm{B}$ & 0.001 to 0.02 & ex & 0.071 & $\mathrm{n}$-ex & -0.01 to 0.04 & 0.04 \\
\hline
\end{tabular}

SG: stroke group, N-SG: non-stroke group, A: comparison is a the 1st and 2nd measurements, B: the maximum obtained during the 1st and 2nd measurements and the 3rd measurrment, LOA: limits of agreement, $\mathrm{MDC}_{95}$ : minimal detectable change $95 \%$

*: exsist: bias is present, $n$-ex: not present

was smaller than the maximum value obtained during the first and second measurements.

\section{DISCUSSION}

The results of this present study indicate that in SG, ICC $(1,1)$ of relative reliability was high at $0.92-0.94$. The results of BAA of absolute reliability indicate that there was no systematic bias on either the non-paralyzed side or the paralyzed side between the first and second measurement values. In addition, the maximum value obtained during the first and second measurements was greater than that obtained during the first measurement. Therefore, these results suggest that when evaluating stroke patients, the required number of measurements is two for the maximum value of the first and second measurements. In addition, the minimal detectable change in the $95 \%$ confidence interval $\left(\mathrm{MDC}_{95}\right)$ on the non-paralyzed side was $0.08 \mathrm{kgf} /$ $\mathrm{kg}$, and $0.07 \mathrm{kgf} / \mathrm{kg}$ on the paralyzed side.

In N-SG, ICC $(1,1)$ of relative reliability was high at $0.93-0.94$. The results of BAA of absolute reliability indicate there was a systemic bias between the first and second measurement values on the right side. No systematic bias was found between the maximum value obtained during the first and second measurements and the third measurement or between the first and second measurement values on the left side. In N-SG, for both sides, the third measurement value was smaller than the maximum value obtained during the first and second measurements. Therefore, these results suggest that when evaluating geriatric patients, the required number of measurements is two for the maximum value of the first and second measurements. In addition, $\mathrm{MDC}_{95}$ on the right side was $0.05 \mathrm{kgf} / \mathrm{kg}$, and $0.06 \mathrm{kgf} / \mathrm{kg}$ on the left side.

In a study on the reliability of knee extension strength measurements, Katoh et al. $\left.{ }^{8}\right)$ suggested that the first measurement value or the average value of two measurements could not be used because the ICC $(1,1)$ of measurements using an HHD with a belt was $0.82-0.92$, and sometimes, the second measurement value was greater than the first measurement value. In addition, based on the results of absolute reliability in knee extension strength measurements, they reported that the required number of measurements was three ${ }^{9}$. In contrast, in a study of the reliability of muscle strength measurements made with an HHD of the upper extremity, Schrama et al. ${ }^{12)}$ reported that the intrarater reliability of an HHD in the assessment of the upper limb muscle strength of healthy subjects was acceptable only for elbow measurements. Hirano et al. ${ }^{11)}$ examined young healthy adults to establish the absolute reliability of shoulder joint horizontal adductor muscle strength measurements and observed a systematic bias between the maximum value obtained during the first and second measurements and the third measurement. The third measurement was smaller than the maximum value obtained during the first and second measurements. As these results showed the limits of agreement (LOA), they recommended that the maximum value of two measurements should be used. Based on our findings, the relative reliability of shoulder joint horizontal adductor muscle strength measurements of hospitalized geriatric and stroke patients was as high as $0.92-0.94$. Similar to previous studies, and considering our results of absolute reliability, it is our recommendation that the adopted values should be the maximum value of two measurements. In addition, to help with the interpretation of the determined effects, $\mathrm{MDC}_{95}$ was evaluated and found to be $0.08 \mathrm{kgf} / \mathrm{kg}$ in $\mathrm{SG}$ and $0.06 \mathrm{kgf} / \mathrm{kg}$ in N-SG.

The present study investigated the reliability of shoulder joint horizontal adduction muscle strength measurements of hospitalized patients. The appropriate number of measurements of shoulder joint horizontal adductor muscle strength measurements was two for geriatric and stroke patients. However, the present study had a limitation in that it did not validate the interrater reliability. Future studies to investigate the relevance of shoulder joint horizontal adductor muscle strength measurements in relation to activities of daily living and respiratory function of geriatric patients and stroke patients will help to clarify the potential clinical application of the present findings. 


\section{REFERENCES}

1) Vaz Fragoso CA, Gill TM: Respiratory impairment and the aging lung: a novel paradigm for assessing pulmonary function. J Gerontol A Biol Sci Med Sci, 2012, 67: 264-275. [Medline] [CrossRef]

2) Howard RS, Rudd AG, Wolfe CD, et al.: Pathophysiological and clinical aspects of breathing after stroke. Postgrad Med J, 2001, 77: 700-702. [Medline] [CrossRef]

3) Ortega F, Toral J, Cejudo P, et al.: Comparison of effects of strength and endurance training in patients with chronic obstructive pulmonary disease. Am J Respir Crit Care Med, 2002, 166: 669-674. [Medline] [CrossRef]

4) Hyde SA, Goddard CM, Scott OM: The myometer: the development of a clinical tool. Physiotherapy, 1983, 69: 424427. [Medline]

5) Wiles CM, Karni Y: The measurement of muscle strength in patients with peripheral neuromuscular disorders. J Neurol Neurosurg Psychiatry, 1983, 46: 1006-1013. [Medline] [CrossRef]

6) Katoh M, Yamasaki H: Comparison of reliability of isometric leg muscle strength measurements made using a handheld dynamometer with and without a restraining belt. J Phys Ther Sci, 2009, 21: 37-42. [CrossRef]

7) Katoh M, Yamasaki H: Test-retest reliability of isometric leg muscle strength measurements made using a hand-held dynamometer restrained by a belt: comparisons during and between sessions. J Phys Ther Sci, 2009, 21: $239-243$. [CrossRef]

8) Katoh M, Isozaki K, Sakanoue N, et al.: Reliability of isometric knee extension muscle strength measurement using a hand-held dynamometer with a belt: a study of test-retest reliability in healthy elderly subjects. J Phys Ther Sci, 2010, 22: 359-363. [CrossRef]

9) Katoh M, Isozaki K: Reliability of isometric knee extension muscle strength measurements of healthy elderly subjects made with a hand-held dynamometer and a belt. J Phys Ther Sci, 2014, 26: 1855-1859. [Medline] [CrossRef]

10) Hirano M, Katoh M: Limits of the manipulative-fixed method for measurement of shoulder joint horizontal adduction muscle strength using a handheld dynamometer. J Phys Ther Sci, 2015, 27: 235-237. [Medline] [CrossRef]

11) Hirano M, Katoh M: Absolute reliability of shoulder joint horizontal adductor muscle strength measurements using a handheld dynamometer. J Phys Ther Sci, 2015, 27: 2125-2127. [Medline] [CrossRef]

12) Schrama PP, Stenneberg MS, Lucas C, et al.: Intraexaminer reliability of hand-held dynamometry in the upper extremity: a systematic review. Arch Phys Med Rehabil, 2014, 95: 2444-2469. [Medline] [CrossRef] 